\title{
KEYWORTH, BEILMAN TO ADDRESS SOCIETY
}

Again this year an all-Society Plenary Session has been arranged for the Monday of the MRS annual meeting in Boston. Immediately following the technical sessions (i.e., at 5:30 p.m.), it will offer all meeting participants an opportunity to hear the views of prominent speakers on issues of general interest to the materials research community. We are pleased to announce that this year's speakers include Donald S. Beilman, President of the Microelectronics Center of North Carolina and George A. Keyworth, Science Adviser to the President of the United States and Director of the federal Office of Science and Technology Policy. "The Role of Industries, Governments and Universities in the Support and the Performance of Materials Research" will be addressed from each speaker's unique perspective.

\section{Donald Beilman}

Donald Beilman, who now heads a center that is the embodiment of an industry/government/university joint venture, left Cornell in 1954 with an electrical engineering degree to begin a 28-year association with General Electric Company. Throughout those years he managed and directed research for several divisions of GE and was vice president, technical systems electronics planning in September of 1982, when he assumed his present position. New algorithms for the pooling of once disparate sources of support are becoming more common and Mr. Beilman is in an excellent position to help us understand the potential effect of these on high technology research and development.

\section{George Keyworth}

George Keyworth received degrees in physics from Yale and Duke Universities and joined the research staff at the Los Alainos Scientific Laboratory in 1968, pursuing fundamental nuclear physics studies. After assuming leadership in 1974 of the Los Alamos program in nuclear

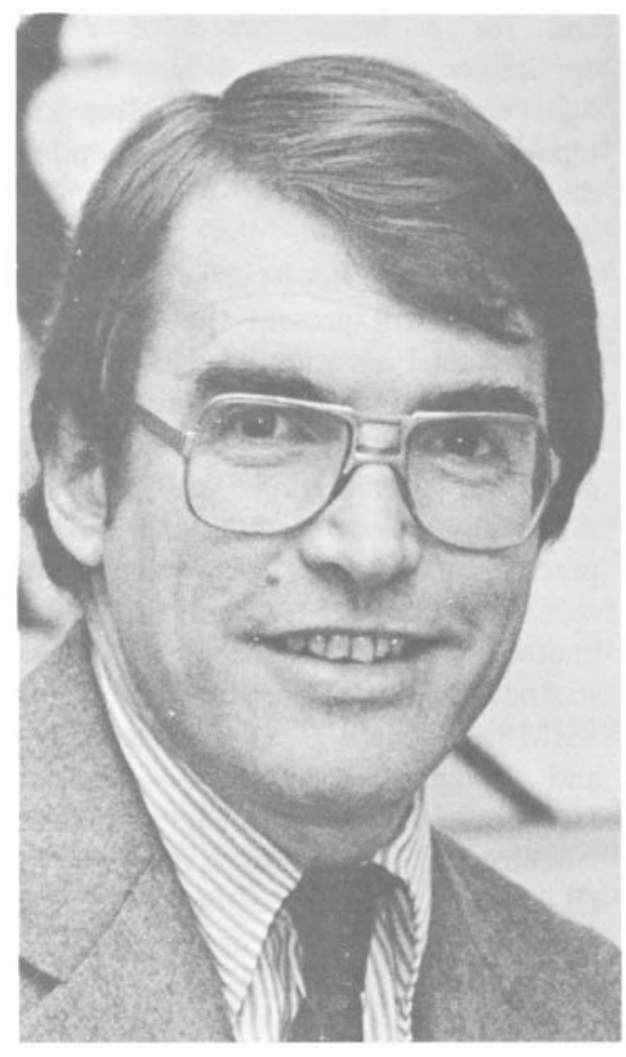

George Keyworth

and fundamental interaction physics, he became, in 1978, head of the experimental physics division. After nomination by President Reagan and confirmation by the U.S. Senate, he assumed the duties of Science Adviser to the President and Director of OSTP in August, 1981. Dr. Keyworth, having examined the special role of the national laboratories and studied the potential of the independent research institute as an alternative for the future, has influenced federal government policies affecting both. The MRS is honored that he has accepted our invitation to present his views on a topic of such importance to our members.

The Plenary speakers, as is our custom, will close their formal session by fielding questions from the audience. A reception for all those in attendance follows where, as has also been our custom, lively discussions of issues

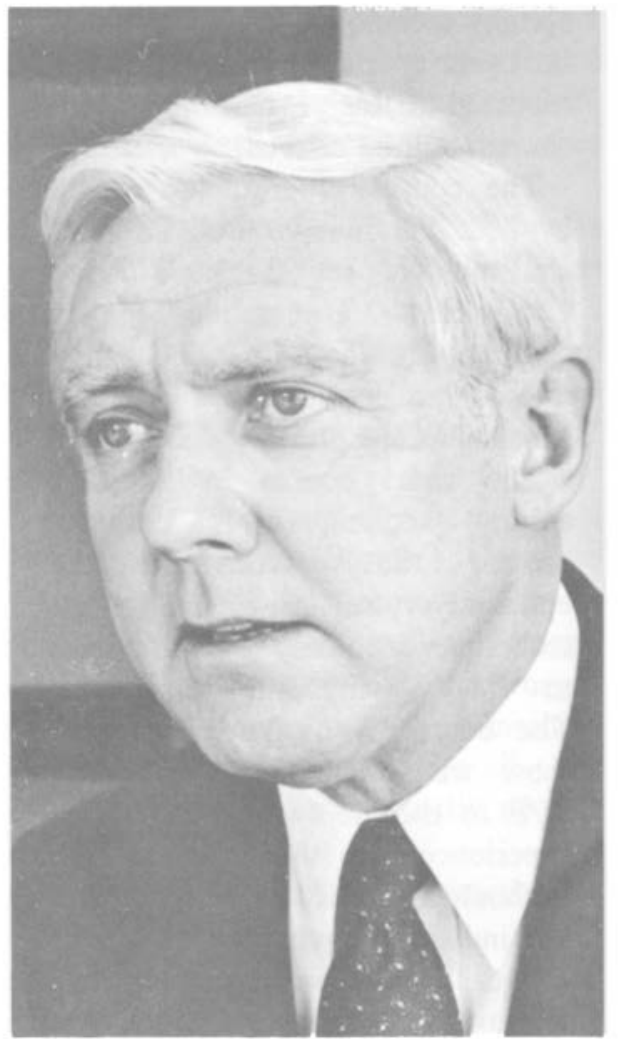

\section{Donald Beilman}

raised by our speakers continues. Questions regarding the Plenary Session may be referred to Elton Kaufmann of the Lawrence Livermore National Laboratory, who will chair the proceedings.

Correction: The last issue of this Bulletin (Jan./Feb. 1983) contained an error. It was erroneously reported on page 19 that Paul Peercy, Jagdish Narayan, and Walter Brown are the organizers of the Albuquerque meeting. In fact, they have been named organizers of the annual meeting to be held in Boston in 1984. Their plans for this meeting will be featured in a forthcoming issue of the Bulletin. The organizers of the upcoming Albuquerque meeting are profiled in this issue. 